\title{
Enhancing Teacher Competency through Co-Teaching and Embedded Professional Development
}

\author{
LaShorage Shaffer ${ }^{1}$, Karen Thomas-Brown ${ }^{1}$ \\ ${ }^{1}$ College of Education, University of Michigan-Dearborn, USA \\ Correspondence: LaShorage Shaffer, University of Michigan-Dearborn, College of Education, Health, and Human \\ Services, Department of Education, Fairlane Center South, 19000 Hubbard Drive, Dearborn, MI 48126, USA
}

Received: February 25, 2015 Accepted: March 11, 2015 Online Published: April 2, 2015

doi:10.11114/jets.v3i3.685

URL: http://dx.doi.org/10.11114/jets.v3i3.685

\begin{abstract}
The ongoing professional development of general education and special education teachers is vital to the success of students with disabilities. As more classrooms transition to a co-teaching model, the professional development that teachers engage in must transition to meet the needs of both groups of professionals. This study used a qualitative approach to examine the practical foundations of a pedagogical style that amalgamates co-teaching and embedded professional development within two inclusive classrooms to theorize the Co-teaching Professional Development (CoPD) Approach. The research findings indicate that within the context of two general education social studies classrooms CoPD offers a suitable approach to supporting teachers and students with disabilities. This piece also points to the existence of reciprocity of content knowledge gains of the special educator and the corresponding gains to the pedagogical repertoire of general educators are presented.
\end{abstract}

Keywords: embedded professional development, co-teaching, general education, special education, co-teaching professional development, CoPD

\section{Introduction}

The teaching profession has evolved and become one in which expertise from multiple fields are integrated to support the educational outcomes of all children. Today the general education classroom is integrated with children with varying abilities. According to the U.S. Department of Education, National Center for Education Statistics (2012), students with disabilities are included in the general education classroom at least $80 \%$ of the school day. This is a $55 \%$ increase since the mid-1980s. Given the change in student population needs, the skills and competencies of general education teachers must be buttressed to meet the diverse needs of the diverse students. The training and expertise that supports children with disabilities are usually acquired by teachers trained in special education (SPED) techniques, thus, often the general education teachers typically do not feel prepared to instruct students with a variety of disabilities and needs (Leko \& Brownell, 2009). Thus, the traditional training and professional development (PD) of educators continues to evolve to meet the needs of the educators in the $21^{\text {st }}$ century classrooms.

The inclusion of children with disabilities within the general education classroom, the training and preparedness of the general education teachers has led to the proposal of the Co-teaching Professional Development (CoPD) approach (Thomas-Brown \& Sepetys, 2011). This model is new in that it combines co-teaching with embedded professional development to create the CoPD model. Previous literature referred either to co-teaching or professional/embedded professional development independently (Billingsley, 2004; Brownell, Adams, Sindelar, Waldron, \& Vanhover, 2006; Harbort, et al., 2007). Within this study, the CoPD approach is the pedagogy in which a veteran special education teacher (VSPED teacher) provides daily professional development training to a general education social studies teacher (GEdSS teacher). The purpose of this paper is to present the practitioner based approach of the Co-teaching Professional Development (CoPD) model and discuss how students with disabilities can obtain effective instructional delivery of social studies content within the general education classroom. The practice of embedded professional development that is advocated in the CoPD approach allows for ongoing training. 


\section{Review of the Literature}

\subsection{Co-Teaching}

With the passing of No Child Left Behind Act of 2001, the inclusion of students with disabilities accessing the general education curriculum within the general education classroom has risen tremendously. As a result many classrooms are trying to discover ways to meet the needs of both the general education students and students with disabilities. One approach that has taken place is the idea of co-teaching. According to Ploessi, Rock, Schoenfeld, and Blanks (2010, p. 158), "over the past decade, co-teaching has become a popular approach to special education service provision in which two teachers work together to support diverse students". Co-teaching according to Leko and Brownell (2009); Mastropieri et.al (2005); Ploessi et al (2010) is an educational approach in which general and special educators work in a co-active fashion, jointly teaching students who are academically and behaviorally diverse.

Friend, Reising, and Cook (1993) have identified five structures to co-teaching (1) one teach, one assist, (2) station teaching, (3) parallel teaching, (4) alternative teaching, and (5) team teaching. In the one teach, one assist structure, the general education teacher would lead instruction while the special education teacher watches and assists students as needed. The station teaching structure is designed so that each teacher is responsible for certain content and divide the teaching based on the components they will teach. In the parallel teaching model, both the general education and the special education teacher plan collaboratively, but work separately with a small group of students to present content. Alternative teaching divides the students into groups allowing the general education teacher to teach the main group of students, while the special education teacher works with smaller groups. Within the team teaching model the "teachers share instruction of students" (Harbort et al., 2007), both taking an equal role in instruction. However, research has found that co-teaching alone only has a moderate impact on student outcomes even when pairing a highly qualified content-area teacher with a certified special education teacher (Walsh \& Jones, 2004; Murawski \& Dicker, 2004; Murawski \& Swanson, 2001).

\subsection{Embedded Professional Development}

Professional development (PD) is a familiar approach to providing teachers additional training to meet specific subject content standards and expectations as well as challenging student behavior. Professional development workshops or seminars are usually held either part-day or full-day. In some cases professional development takes place when teachers attend a conference of a state or national organization. However, the likelihood that knowledge and skills are generalized and transferred to the classroom setting is minimum.

An alternative to traditional PD is job embedded professional development (JEPD), (Croft, Coggshall, Dolan, Powers, \& Killion, 2010). Job embedded professional development has been defined as teacher learning that is grounded in day-to-day teaching practice and is designed to enhance teachers' content-specific instructional practices with the intent of improving student learning (Darling-Hammond \& McLaughlin, 1995; Hirsh, 2009). Through JEPD teachers are able to connect research to practice on an ongoing basis in collaboration with other professionals. Brown-Easton (2008) and Wei et al. (2009) have identified 12 JEPD formats: (1) action research, (2) case discussions, (3) coaching, (4) critical friends groups, (5) data teams/assessment development, (6) examining student work/tuning protocol, (7) implementing individual professional growth/learning plans, (8) lesson study, (9) mentoring, (10) portfolios, (11) professional learning communities, and (12) study groups. Each of these formats requires teachers to be open to critical feedback and willing to share lesson plans, and tests, etc. in order to improve their teaching and ultimately improve the educational environment for all students. Regardless of which format is used, in order for learning to take place PD must be grounded in theoretical knowledge based in actual events, self-directed and significant to the teacher, and build upon pre-existing knowledge (Croft, Coggshall, Dolan, Powers, \& Killion, 2010).

\subsection{Structure of Co-teaching Professional Development (CoPD) Model}

In order to address the varying needs of students with disabilities teachers must reflect upon their practices and seek professional development that meets their needs. However, Leko and Brownell (2009) have found that many teachers acknowledge "they need to improve their practice for students with disabilities, but they often believe that school-wide professional development (PD) efforts have failed to meet their specific needs" (p. 64). The traditional model of professional development is often delivered in a half-day meeting covering a targeted strategy or particular teaching strategy with no opportunities for follow up or questions regarding implementation (Garet et al., 2001; Waitoller \& Artiles, 2013). As the face of the general education classrooms have changed, the professional development in which teachers participate must change as well. One potential form of professional development that has promising outcomes is embedded professional development (EPD) (Darling-Hammond \& McLaughlin, 1995; Hirsh, 2009). Research in the use of embedded professional development is on the forefront of how professional development will look in schools. The implementation of EPD takes long-term strategic planning and buy-in from all parties. Highly qualified general education teachers and special education teachers must work alongside each other and support the development of their co-teacher. 
In the short term, EPD may seem expensive but in the long term it provides training to the general education teacher and special education teacher that would be otherwise difficult, leaving both educators more competent to instruct all students in their classrooms. Thus, combining co-teaching and EPD creates the Co-teaching Professional Development classrooms (CoPD) model.

In the Co-teaching Professional Development (CoPD) model, EPD is facilitated through the process of co-teaching which allows the special education teacher to share knowledge and skills with the general education teacher in the "how to" of accommodating students with disabilities and the general education teacher sharing knowledge of the specific content begin taught and strategies to help students learn the content. The benefits of this are confirmed by Ploessi et al. (2010) who notes that "combining the strengths of general and special educators in the classroom can be deeply beneficial to students and teachers alike" (p. 158).

According to De La Paz, Morales and Watson (2007) "reform in social studies education is changing the way in which students learn history and providing new reasons for learning history" (p. 134). Social studies is aimed at producing the 'good citizen' through the study of people in their temporal, spatial and socio-economic locals. It is therefore appropriate that social studies classrooms are the venue for evaluating the extent to which inclusion facilitates academic success among students with disabilities. Thus, the Co-teaching Professional Development model addresses these issues by training the general education teachers, while the special education teacher acquires some content knowledge and vice versa. The CoPD approach suggests that the special educator be placed in the general education classroom (as co-instructor with the general education teacher) providing specialized instruction in a general education setting and modeling pedagogy for the general education teacher who over time will be able implement some of these strategies independently.

Therefore, this study empirically investigates the Co-teaching Professional Development model in an inclusive social studies classroom. According to Steele (2007); Thomas-Brown and Sepetys (2011), the Individuals with Disabilities Education Act (IDEA, 2004) has provided students with disabilities to opportunity to be included in history, political science, geography and economics (social studies) classes, however, this has created challenges for teachers who find it difficult to instruct students with disabilities. This study adds to the literature which exists on the attitudes and dispositions of general education and special education teachers collaborating in inclusive education classrooms, specifically teaching social studies with the CoPD approach to support student acquisition of content.

\section{Method}

\subsection{Participants and Settings}

There were two teams that participated in this study consisting of two general education teachers and a shared special education teacher. Both general teachers were certified to teach social studies in secondary education and the special education teacher held certification in elementary education and a Master's degree in special education. The special education teacher has been teaching for 17 years and has taught in both elementary and secondary settings. All teachers were certified to teach in the state of Michigan.

\section{Teaching Team A}

Team A (Nicole \& Andrea), taught together daily for a 50-minute time block. Andrea, the general education teacher has been teaching for 30 years. Andrea volunteered to participate in this study from August 2010-January 2011. The class in which Team A taught held 19 students, eight of whom had a disability. Andrea and Nicole were designated as veteran teachers given they both have been teaching in the field for over 10 years.

\section{Teaching Team B}

Teaching Team B (Nicole \& Tom), taught together daily for a 50-minute time block. Tom, the general education teacher is new to the teaching profession, having taught for 4 years. Tom joined the study in September 2010-January 2011. His classroom consisted of 29 students, nine of whom had a disability. Tom was designated as a novice teacher given that he has been teaching less than 10 years.

Both classrooms were secondary social studies classes. Tom and Andrea's primary pedagogies included lectures, note taking, map work, worksheets, reading, discussions and tests. The classrooms were situated in a school located in an affluent suburban community. The school held approximately 250 students, $90 \%$ of whom are Caucasian. The students socioeconomic status (SES) were mainly from middle and upper middle class homes, with less than 3 percent of the students in the school qualifying for free and reduced lunch.

\subsection{Procedures}

\subsubsection{Teachers Perspectives of Inclusion and Co-Teaching}


Informal hallway conversations and the first formal meeting among the two teams of teachers allowed the researchers to ascertain how the teachers felt about working with students with disabilities as well as in a teaching-team. According to Mastropieri et al. (2005), it is important that teachers working within a classroom partnership be open and enthusiastic about working together. In addition to the informal conversations, teachers brought materials necessary to prepare for the first quarter of the school year. According to Ploessi et al. (2010), "to effectively provide special education services, co-teachers must work closely together, combining techniques, goals and curricula". This initial meeting was vital to establishing the co-teaching relationship.

\subsubsection{Expectations and Roles of Each Teacher}

During the subsequent meetings the two teaching teams discussed expectations for classroom interactions and instruction. Ploessi et al. (2010) indicated that "focusing on seemingly simple skills such as effective speaking and listening builds a solid foundation for improving co-teaching interactions" (p. 159). Who will handle what? How will daily instruction occur? How will day to day planning occur? When will there be time to discuss how the day went? Who will complete grading? Shared? Are both teachers speaking to the class as a whole or is it only the general education teacher? These meetings were seen as important in the perception that students might have of the class and teachers.

\subsubsection{Implementing the CoPD Model}

The general education teacher is considered the expert in content and the special education teacher is the expert in pedagogy and differentiating instructions, this corresponds with the discourse put forward by Mastropieri et.al. (2005). Merging these skills required patience and some trial and error. Discussions of how to handle the inevitable issues that arise between the two were warranted. Teaching teams were required to meet at the end of the day to debrief and establish each person's perspective/s and possible modifications that may be deemed necessary. It was important that the special education and the general education teachers meet briefly each day during the first couple of weeks of classes to debrief, plan and modify instruction on an ongoing basis. For Ploessi et al. (2010) designing and planning lessons together allowed for more effective co-teaching, hence the necessity of these debriefing sessions.

\section{Data Collection}

Data was collected through informal conversations, self-report, and semi-structured interviews. Anecdotal notes were taken during informal conversations and interviews were audiotaped. Six semi-structured interviews were conducted with each teacher which were audiotaped and then transcribed verbatim. These interviews were approximately one hour. Interviews were conducted based on the participants' availability and choice of location.

\section{Data Analysis}

\subsection{Analysis of Interviews}

As each interview was transcribed ongoing analysis took place (Charmaz, 2004; Ezzy, 2002; Morse \& Richards, 2002). The process of transcribing provided an opportunity to study the data and generate themes. Once transcription was complete, each transcript was read while the researcher listened to the matching audiotape. This process ensured accuracy of the information collected. Thematic analysis of the data was conducted in order to substantiate themes based on the participants' own words. According to Strauss \& Corbin (1998), the process of "open coding" allows for categories to be generated. Memos were written to keep track of "theoretical questions, hypotheses, and summary of codes" (Ezzy, 2002, p. 72). This process is a crucial step between coding the data and focused coding (Charmaz, 2004: Ezzy, 2002). Data was reviewed and coded line-by-line for relationships between codes and the association of new codes that emerge from the data. Categories helped delineate common themes and patterns.

In order to better organize the data during analysis, the researchers developed a matrix to "sort and sift" through responses within the appropriate category. Teachers responses where quoted within the matrix. Next, categories were aligned with research questions in order to determine if teachers' responses were answering the research questions and which categories aligned with which research questions. Responses that were mentioned by more than one participant were highlighted in similar colors. Finally, categories were broken down into common themes and the patterns reflected from teacher responses were sorted according to the pattern they fell into.

\subsection{Focused Coding}

Earlier codes were reviewed for frequency in the data by the researcher. These codes were used to categorize earlier data and review data with a new perspective. As more data was collected, these categories helped in developing an analytic framework for synthesizing the data in a descriptive manner. The researchers coded $100 \%$ of the units of analyses, categories, and then discussed the categories until 100\% agreement was reached. By refining the categories through this process, all of the responses were coded. 


\subsection{Creation of Codes and Categories}

During the process of reading the transcripts, notes and codes were marked on each transcript. Codes were assigned based on the meaning or "inferential information compiled" from the interviews (Miles \& Huberman, 1994, p. 56). The process of "sorting and sifting through these materials to identify similar phrases, relationships between variables, patterns, themes..." (Miles \& Huberman, p. 9) was used.

A minimum of three independent readings of the transcriptions took place by each researcher. Notes were taken in the margins of transcriptions when repetitive responses were present in relationship to specific questions. As patterns were revealed in the responses of participants codes and categories emerged including; motivation, teamwork, receptiveness, creativity, and challenging behavior.

\subsection{Establishing Trustworthiness.}

In order to establish category integrity, a naïve independent coder was asked to read and code an average of $25 \%$ of the units of analyses. Kazdin (1982) recommends reviewing $20 \%$ of the data. This step is also described by Miles and Huberman (1994) as the gradual elaboration on a small set of generalizations that deal with the consistencies reflected in the database (the interviews).

\section{Results}

The study found that fundamental to the co-teaching professional development (CoPD) model is team work and the acknowledgement of the roles each teacher plays in this model. Team work between the co-teachers was critical to the success of the CoPD model. To demonstrate this finding, Tom stated that "I have really enjoyed teaching together. I feel like I've learned a lot and it has helped me look at my teaching ideas in different ways. I would like to co-teach again with someone." In other instances, Nicole took time to observe Tom's teaching technique and then gave strategies to engage all students in the content. For example she stated,

When I first joined the class I observed Tom, the social studies teacher, for a week or so as he taught a unit on ancient China. As he discussed events taking place in the 1200's I noticed many of the students (both with disabilities and without) did not seem engaged or interested in what he (Tom) was discussing. I remember thinking that the ideas he was teaching about were quite abstract to the students living in 2010 (Nicole).

This is an example of successful teamwork in the CoPD model and demonstrates that the general education social studies teacher has content knowledge and the veteran special education teacher has expertise in pedagogy, by combining the two, the model was able to accommodate all the students as Tom presented this and other abstract social studies topics.

Another finding regarding the practice of CoPD corresponds to the receptiveness of all participants. The experiences of Andrea and Tom yielded contrasting responses to the CoPD model. At the beginning of the school year Andrea stressed to the social studies students that correct spelling on all assignments was required. If a student misspelled anything they received half credit for the correct answer. As a result of Andrea's approach, the students were receiving low grades and many were not passing social studies because they struggled with spelling. This discouraged a number of the students, especially those who are challenged by their disabilities. During their CoPD planning time Nicole suggested that they reconsider the spelling requirement for this social studies class. Several discussions occurred in which Nicole discussed the students' objectives along with the required state benchmarks that were being targeted. After several weeks of dialogue, Andrea agreed to this suggestion and for those students with a disability correct spelling was no longer a requirement. Andrea was not as receptive to the CoPD model stating, "I feel that this is one more prep that I have to do on top of six already! I really don't have the time or energy to fit in more conference time to plan for this one hour." This kind of reaction is not uncommon, according to Ploessi et al. (2010) "co-teaching may be popular but it does not come naturally... the greatest obstacle to co-teaching is the lack of preparedness of the educators involved... because it requires an additional set of skills that are rarely used when teaching alone" (p. 158).

Tom on the other hand was receptive to the CoPD model. Nicole and Tom discussed her impressions of his lessons. During these discussions Nicole suggested that they could create interest and involvement with an activity that allowed the students to discover what other events were happening globally during that time period (1200s) to give students perspective on the times and places they were studying both then and in the future. As indicated by Nicole,

Tom was receptive. We had the students create a timeline chart that eventually spread around the entire classroom.

This chart allowed the students to visibly compare a variety of historical events in the timeline that ultimately covered from the early 1000's to the current day.

Hence, Nicole believes CoPD would be more effective if both teachers are able to embrace their roles within this classroom. Having implemented and refined a co-teaching model over the several years, Nicole stated "the success of 
CoPD in social studies or any classroom for that matter is dependent on the receptiveness of the content area teacher". This finding corresponds with those of Mastropieri et.al. (2005) who indicates that volunteer co-teachers report more positive perceptions than teachers who are assigned co-teaching classrooms, given this fact "co-teaching partners can be trained to increase their efficiency" particularly as it pertains to establishing their roles and interacting with students ( $\mathrm{p}$. 261).

The study also found that within the CoPD model teachers must be creative in designing motivating activities for all students. One of Nicole role was to define the requirements for students with disabilities to ensure that they made progress in the general education curriculum. By being an active participant in the social studies classroom she was able to modify the curriculum and assignments in real time, allowing for adaptations to the needs of the students as they occurred. According to Nicole,

Tom and I did not use the text book often. There was only one room set which was used about 3 times. Andrea, assigns students a book for the year and on an average of three times a week she requires them to answer questions from a worksheet she created. The worksheet is tailored to the chapter in a sequential order so that students may follow along with the book and fill in the answers. There is some time to work during class but any remaining work needs to be done at home.

In this instance, the CoPD model allowed for modifications to suit the content area teacher's approach to teaching social studies. Nicole was able to implement more creative modifications in Tom's social studies class, as opposed to in Andrea's classroom, where her role was less creative and more supportive. She made accommodations for the students with disabilities, thus providing the students with "the distinctiveness and intensity considered to be important features of special education" Mastropieri et.al. (2005, p. 261). As stated by Nicole,

I personally like to have students find a way to interact with the text, which is what Andrea does. For students with disabilities this kind of text book interaction might include the use of sticky notes to highlight certain subjects, or I have the special education department buy the students their own copy of the text so they can write in the book.

Irrespective of the strategies that have been used, many students with disabilities experience difficulties comprehending social studies materials related to abstract events that might impact the world. These students also encounter difficulties critically thinking through common themes in history and social studies. Discussions of countries that are far away are in the realm of abstract for many students with disabilities. In order to address the abstract nature of the content, Nicole stated, "I try to make the subject as relevant to them as possible, providing lots of pictures, videos, and projects to make the subject come alive". The teachers were also able to make modifications to ensure that their students had the opportunity to keep pace with the rest of the class. While improving teacher effectiveness, effective inclusion of students with disabilities is facilitated through school achievement and to optimizing students' learning of co-taught content, monitoring student progress, and reflecting on lessons that have been co-taught (Ploessi et al., 2010).

Therefore, in this instance the CoPD teachers encouraged the students to adapt the strategies they have been introduced to that worked best for them; this for Allington (2007) focuses on matching the students with the most appropriate curriculum materials. The strategy of writing everything down also extended to the use of study guides which the CoPD teachers created for those students who needed to have their learning materials streamlined.

A recurring theme in the data was the impact of inclusion on the social skills and behavior of all students in the CoPD classrooms. According to Nicole,

There were disruptive students who were not the ones with disabilities too! It does add to the workload of teachers, but these strategies actually work for all the students... we tried to create situations where we could work on social skills on a regular basis. One of my jobs was to encourage all students, particularly BD (behavior disorder) individuals. Every day the goal was for all students to participate and connect during the entire class; does it happen? No. But we tried to come up with activities that challenged the students' to be cognitively engaged.

In order for teachers to focus on the content to be taught, classroom management must be addressed. Dealing with challenging behavior negates the ability for any teacher to concentrate on instruction and elaborate on content. Support of a highly trained co-teacher aides in addressing challenging behavior and redirecting the focus on providing an opportune instructional environment for all learners.

\section{Discussion and Closing}

Inclusive educational environments must address the diverse learning styles of all students, thus requiring schools to support both teachers and students in the context of the classroom. Identifying approaches that will aide in this effort is important for educational success of all students. Co-teaching Professional Development (CoPD) is one way to address inclusive education. The availability of two teachers within the classroom increases the opportunities for students to be successful. Integrating both a highly qualified general education and special education teacher addresses the need within 
inclusive educational environments. Through CoPD, classroom practices incorporate scaffolding, modifying instruction for optimal learning, utilizing technology and visuals for the varying learning styles of all students.

The success of Co-teaching Professional Development (CoPD) depends on the crucial rhetoric; do both teachers want to do this? How comfortable is their relationship? Have they invested time in the practice? Co-teaching Professional Development (CoPD) strategies used in the general education social studies classrooms allowed the subject material to be modified when appropriate and accessible to students with disabilities who would ordinarily not function well within this classroom setting. The strategies critical to the success of CoPD also assist those students who are at risk for failure and dropout. This is because the presence of an additional teacher provides them with more support. Mastropieri et al. (2005) also indicated that the additional support in the classroom leads to high quality instruction for all students.

The CoPD model advocates that students with disabilities should take the subjects they need in order to prepare for the future they are interested in pursuing. If they are uncertain about the future they want to pursue, they should have the option of trying a variety of classes and disciplines. A student with cognitive impairments might experience difficulties with the academic expectations of a general education classroom. However, with the support and modifications from CoPD approach, they might make appropriate educational gains.

The Co-teaching Professional Development (CoPD) approach has the potential to enhance inclusive educational settings by providing immediate support to children with disabilities, along with a co-constructed professional development system for the general education and special education teachers.

This study presents a model for using the Co-teaching Professional Development (CoPD) approach which allows for the transference of skills for both general education and special education teachers to successfully instruct all students. While there were successes from the implementation of this model, they were anecdotal and are limited to this one school and group of teachers. One of the limitations of this study was the sample size of participants. Only two general education teachers and one special education teacher participated in this study. Thus, a larger sample size of partnering professionals and schools would be needed. Another limitation was the lack of data on student success. Data showing actual outcomes of student engagement and progress would add to the quality of the study. In addition, student feedback would enhance the quality of the data and the impact of the CoPD approach on classroom instruction and overall learning. The implications of this for future research is expanding the use of this model into other social studies classrooms, other disciplines and other schools to determine the extent to which the outcomes chronicled in this study are replicated. Further research would also require an evaluation of student outcomes as part of this model in other settings, including the types of modifications used, how the CoPD model is structured, implemented, and analyzed to increase its effectiveness in accommodating students with disabilities in general education classrooms.

Co-teaching Professional Development (CoPD) can provide educators with a multiplicity of opportunities to improve on how they meet the academic and behavioral needs of an increasingly diverse student populations. The benefits to the participating teachers in CoPD could be bountiful. Co-teaching Professional Development (CoPD) allows the general education and special education teacher to increase his/her knowledge of the content, in this case social studies while building the pedagogy skills of the content area teacher. After time spent working day-to-day with the special education teacher, the various techniques and strategies to improve instruction for all students can become more readily accessed in their daily repertoire, in turn, creating rooms throughout the school that are appropriate placements for all students. CoPD enables the participating teachers to have real learning opportunities in the classroom.

\section{References}

Allington, R. (2007). Intervention all day long: new hope for struggling readers. Voices from the Middle, 14(4), 7-14.

Billingsley, B. S. (2004). Special education teacher retention and attrition a critical analysis of the research literature. The Journal of Special Education, 38(1), 39-55. http://dx.doi.org/10.1177/00224669040380010401

Brown-Easton, L. (2008). Powerful designs for professional learning (2 ${ }^{\text {nd }}$ Ed.). Oxford, Oh: National Staff Development Council.

Brownell, M. T., Adams, A., Sindelar, P., Waldron, N., \& Vanhover, S. (2006). Learning from collaboration: The role of teacher qualities. Exceptional Children, 72(2), 169-185. http://dx.doi.org/10.1177/001440290607200203

Charmaz, K. (2005). Grounded theory in the $21^{\text {st }}$ century: Applications for advancing social justice studies. In N. K. Denzin \& Y. S. Lincoln (Eds.), Handbook of qualitative research (3rd Ed.). Thousand Oaks, CA: Sage Publications, Inc.

Croft, A., Coggshell, J. G., Dolan, M., Powers, E., \& Killion, J, (2010). Job-embedded professional development: What it is, who is responsible, and how to get it done well. National Comprehensive Center for Teacher Quality.

Darling, H. L., \& McLaughlin, M. W. (1995). Policies that support professional development in an era of reform. Phi 
Delta Kappan, 76, 597-604.

De La, P. S., Morales, P., \& Winston, P. (2007). Teaching students with and without LD to read and write historically. Journal of Learning Disabilities, 40(2), 134-144. http://dx.doi.org/10.1177/00222194070400020401

Ezzy, D. (2002). Qualitative analysis: Practice and innovation. London: Routledge.

Friend, M., Reising, M., \& Cook, L. (1993). Co-teaching: An overview of the past, a glimpse at the present, and considerations for the future. Preventing School Failure, 34(4), 6-10. http://dx.doi.org/10.1080/1045988X.1993.9944611

Garet, M., Porter, A., Desimone, L., Birman, B., \& Yoon, K. (2001). What makes professional development effective? Analysis of a national sample of teachers. American Education Research Journal, 38(4), 915-945. http://dx.doi.org/10.3102/00028312038004915

Hammill, D. D. (1990). On defining learning disabilities: An emerging consensus. Journal of Learning Disabilities, 23(2), 74-84. http://dx.doi.org/10.1177/002221949002300201

Harbort, G., Gunter, P. L., Hull, K., Brown, Q., Venn, M. L., Wiley, L. P., \& Wiley, E. W. (2007). Behaviors of teachers in co-taught classes in a secondary school. Teacher Education and Special Education, 30(1), p. 13-23, http://dx.doi.org/10.1177/088840640703000102

Hirsh, S. (2009). A new definition. Journal of Staff Development, 30(4), 10-16.

Individuals with Disabilities Education Improvement Act (2004). P. L. 108-446, 118 Stat. 2647.

Kazdin, A. E. (1982). Single-case research designs: Methods for clinical and applied settings. New York: Oxford University Press.

Leko, M., \& Brownell, M. (2009). Crafting quality professional development for special educators: What school leaders should know. Teaching Exceptional Children, 42(1), 64-70.

Mastropieri, M. A., Scruggs, T. E., Graetz, J., Norland, J., Gardizi, W., \& Mcduffie, K. (2005). Case Studies in CoTeaching in the Content Areas Successes, Failures, and Challenges. Intervention in School and Clinic, 40(5), 260-270. http://dx.doi.org/10.1177/10534512050400050201

Miles, M. B., \& Huberman, A. M. (1994). Qualitative data analysis: An expanded sourcebook. (2 ${ }^{\text {nd }}$ Ed.). Thousand Oaks, CA: Sage.

Morse, J. M., \& Richards, L. (2002). Read me first for a user's guide to qualitative research. Thousand Oaks, CA: Sage.

Murawski, W. W., \& Dicker, L. A. (2004). Tips and strategies for co-teaching at the secondary level. Teaching Exceptional Children, 36(1), 52-58.

Murawski, W., \& Swanson, L. (2001). A meta-analysis of co-teaching research: Where are the data? In Mastropieri, T. et.al. (2005). Case studies in co-teaching in the content areas: Successes, failures and challenges. Intervention in School and Clinic, 40(5), 260-270.

No Child Left Behind, 20 U. S. C. $\$ 6301$ (2001).

Office of Special Education Programs. (2004). Twenty-Sixth annual Report to Congress on the Implementation of the Individuals with Disabilities Education Act. Washing, DC: U.S. Department of Education.

Ploessi, D., Rock, M., Schoenfeld, N., \& Blanks, B. (2010). On the same page: Practical techniques to enhance coteaching interactions. Intervention in school and clinic, 45(3), 158-168. http://dx.doi.org/10.1177/1053451209349529

Rubin, H. J., \& Rubin, I. S. (1995). Qualitative interviewing: The art of hearing data. Thousand Oaks, CA: Sage.

Steele M. 2007. Teaching social studies to high school students with learning problems. The Social Studies, 98(2), 59-63. http://dx.doi.org/10.3200/TSSS.98.2.59-64

Strauss, A. \& Corbin, J. M. (1998). Basics of qualitative research: Grounded theory procedures and techniques $\left(2^{\text {nd }}\right.$ Ed.). Thousand Oaks, CA: Sage.

Thomas, B. K., \& Sepetys, P. (2011). A veteran special education and a general education social studies teacher model co-teaching: The CoPD model. Journal of the Association of American Special Education Professionals http://aasep.org/aasep-publications/journal-of-the-american-academy-of-specialeducation-professionals-jaasep/jaasep-fall-2011/a-veteran-special-education-teacher-and-a-generaleducation-social-studies-teacher-model-co-teaching-the-copd-model/index.html 
U. S. Department of Education, National Center for Education Statistics. (2012). Digest of Education Statistics, 2011 (NCES 2012-001), Chapter 2. Retrieved from http://nces.ed.gov/fastfacts/display.asp?id=59

Waitoller, F. R., \& Artiles, A. J. (2013). A Decade of Professional Development Research for Inclusive Education A Critical Review and Notes for a Research Program. Review of Educational Research, 83(3), 319-356, http://dx.doi.org/10.3102/0034654313483905

Walsh, J. M., \& Jones, B. (2004). New models of cooperatively teaching. Teaching Exceptional Children, 36, 14-20.

Wei, R. C., Darling, H. L., Andree, A., Richardson, N., \& Orphanos, S. (2009). Professional learning in the learning profession: A status report on teacher development in the United Stated and abroad (Technical Report), Dallas, TX: National Staff Development Council. http://www.nsdc.org/news/NSDCstudytechnicalreport2009.pdf

\section{(cc) BY}

This work is licensed under a Creative Commons Attribution 3.0 License. 